cooking and heating services is widespread throughout rural China. However, its use has Recent Reductions in China's Greenhouse Gas Emissions

\author{
David G. Streets ${ }^{1 *}$, Kejun Jiang ${ }^{2}$, Xiulian $\mathrm{Hu}^{2}$, Jonathan E. Sinton ${ }^{3}$, \\ Xiao-Quan Zhang ${ }^{4}$, Deying $\mathrm{Xu}^{4}$, Mark Z. Jacobson ${ }^{5}$, James E. Hansen ${ }^{6}$
}

$25,300 \mathrm{Tg}(1)$. In the period 1995 to 1999 , $\mathrm{CO}_{2}$ emissions from fossil fuel combustion in western Europe increased by $4.5 \%$, in the United States by $6.3 \%$, in Japan by $3.0 \%$, and in India by $8.8 \%(4)$.

When energy data for the past 5 years began to emerge from China, it became clear that a transformation was in progress that had resulted in a reduction in energy use (2). This transformation had several aspects to it: the closing of small, inefficient industrial plants; improved efficiency of energy enduse; improved coal quality; the switching of many residential fuel users from coal to gas and electricity; technological progress in the energy-intensive sectors; and the opening up of coal and electricity markets. A slowdown in economic growth contributed to the decline in energy use (5). We have converted the changes in energy use and other activities into greenhouse gas emissions using guide-

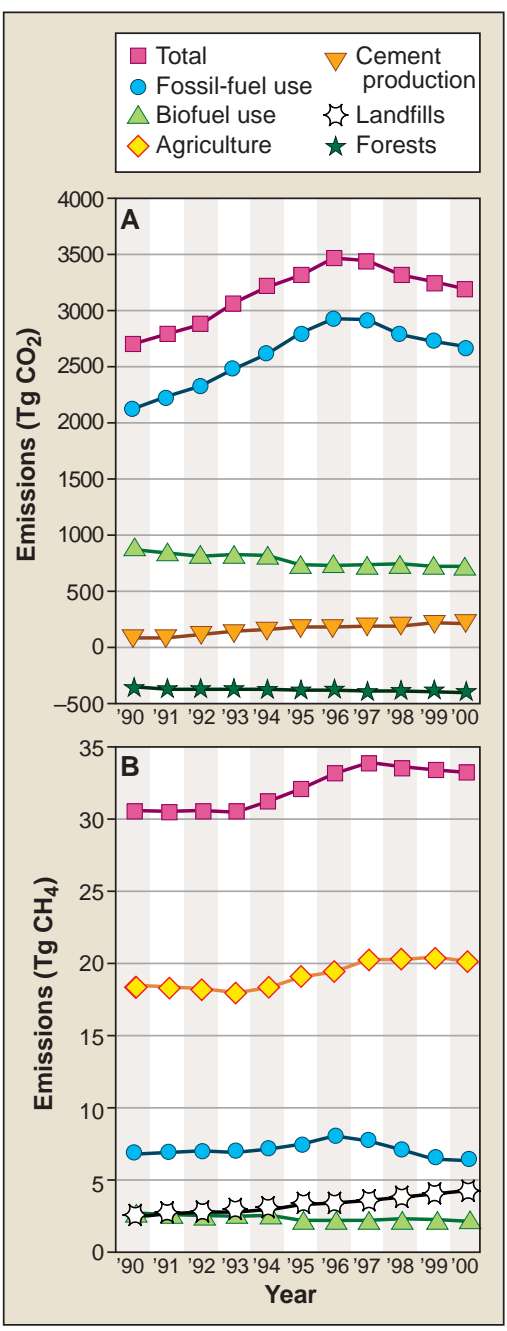

Trends in emissions of (A) $\mathrm{CO}_{2}$ and (B) $\mathrm{CH}_{4}$ in China, 1990 to 2000. slowly declined during the decade, from 9.2 EJ in 1990 to about 7.6 EJ in 2000 (8), as kerosene, gas, and electricity have supplanted traditional fuels. Carbon dioxide is also released during the manufacture of cement, and China's use of cement for new construction grew from 210 million tons in 1990 to 600 million tons in 2000 (9). As a result of the reversal of past deforestation practices and recent promotion of afforestation activities, the net uptake of $\mathrm{CO}_{2}$ by forests in China has increased from $360 \mathrm{Tg}$ in 1990 to $410 \mathrm{Tg}$ in 2000 (10). Overall, we estimate that $\mathrm{CO}_{2}$ emissions grew from 2710 $\mathrm{Tg}$ in 1990 to a peak of $3470 \mathrm{Tg}$ in 1996 , thence dropping to $3220 \mathrm{Tg}$ in 2000 (see the figure), a $7.3 \%$ reduction in the period 1996 to 2000 (11). This recent trend illustrates the potential for a fundamental change in the long-term pattern of emissions growth in China.

In the last few years, China's energy data have become more prone to error and uncertainty than they were in the early 1990 s. The National Bureau of Statistics has already revised 1999 coal output and consumption estimates (8). This has caused some skepticism about the reduction in energy use (12). Our analysis suggests that the reductions are real but not as great as previously believed. Furlines from the Intergovernmental Panel on Cli- ther revisions to recent energy-use data are mate Change (IPCC) (6), as modified for Chi- possible, which would necessitate a reanalyna-specific conditions in the U.S.-sponsored China Climate Change Country Study (7).

Coal combustion is the dominant contributor to $\mathrm{CO}_{2}$ emissions in China and is estimated to have grown from 22.1 exajoules ( $1 \mathrm{EJ}=10^{18}$ joules) in 1990 to a peak of $30.1 \mathrm{EJ}$ in 1996 and then to have fallen to $25.1 \mathrm{EJ}$ in 2000 (8). Oil and gas combustion both increased steadily during the decade, but their contributions to $\mathrm{CO}_{2}$ emissions are small. The use of biofuels (largely wood and agricultural residues for fuel) to provide possible, which would necessitate a reanaly-
sis of the data; however, we do not expect the trend to change.

Estimating $\mathrm{CH}_{4}$ emission trends is a more difficult proposition, because it involves consideration of several nonenergy sources for which there are limited data available. Coal production is a large source of $\mathrm{CH}_{4}$, and it is known that coal production in China declined in recent years by an even larger amount than coal consumption, from 1370 million tons in 1996 to 1030 million tons in $2000(8)$. This decline was due to
*To whom correspondence should be addressed. Email: dstreets@anl.gov. 


\section{SCIENCE'S COMPASS}

overmining in the early part of the decade, which produced large stockpiles of coal that are now being drawn down (2). However, the benefit to $\mathrm{CH}_{4}$ emissions was not proportionately large, because much of the reduction in coal production was achieved at small, surface mines, owned by local governments and townships, which tend to emit less gas. Thus, over all mine types, we found a net increase in coal-bed emissions from $5.58 \mathrm{Tg} \mathrm{CH}_{4}$ in 1990 to $6.75 \mathrm{Tg}$ in 1996 , falling to $5.45 \mathrm{Tg}$ in 2000 (13). Emissions from oil and gas extraction, processing, distribution, residential leakage, and combustion were also calculated, but these are small compared with coal emissions. Emissions from residential biofuel combustion were reduced from $2.76 \mathrm{Tg}$ in 1990 to $2.28 \mathrm{Tg}$.

Agricultural emissions of methane grew in the middle of the decade but have leveled out recently. Emissions from rice cultivation declined slowly from $11.2 \mathrm{Tg}$ in 1990 to $10.1 \mathrm{Tg}$ in 2000 , on the basis of annual trends in cultivated area (9). Emissions from livestock were calculated for three animal classes-large animals, sheep and goats, and pigs - following the method and emission rates used in the China Country Study (7), which includes both enteric fermentation and manure contributions. The numbers of animals have increased substantially during the decade (9), leading to an increase in $\mathrm{CH}_{4}$ emissions from 5.80 $\mathrm{Tg}$ in 1990 to $8.55 \mathrm{Tg}$ in 2000.

Two final contributions to $\mathrm{CH}_{4}$ emissions were estimated, both of which are more uncertain: landfills and biomass burning. We estimate a large increase in landfill emissions from $2.43 \mathrm{Tg}$ in 1990 to $4.35 \mathrm{Tg}$ in 2000 , due to changes in both the amount and composition of municipal garbage generated. Methane is also produced by the burning of biomass - whether of agricultural residues in the field after harvest, land clearing for production of new agricultural fields, deforestation, or simply wildfires in grassland and forests. Because this source is difficult to quantify and subject to interannual variability, we have adopted the estimate of Olivier et al. (14) for 1990 and have included it at a constant annual value of $1.60 \mathrm{Tg}$ across the decade. The combined estimate from all these source categories shows $\mathrm{CH}_{4}$ emissions in China rising from $30.7 \mathrm{Tg}$ in 1990 to a peak of $34.1 \mathrm{Tg}$ in 1997 and then falling to $33.3 \mathrm{Tg}$ in 2000 (see the figure on page 1836 ), a $2.2 \%$ reduction in the period 1997 to 2000 .

What do we expect for the future? Emissions of $\mathrm{CO}_{2}$ (and probably $\mathrm{CH}_{4}$ ) in China are thought to have been roughly constant since 2000 (15). Some of the most painful reforms have already been made, and the economy is once again picking up speed-although accession to the World Trade Organization is likely to bring a fresh wave of reforms to many sectors of the economy. A return to a slow increase in fossil fuel use has been projected (15), but on a much shallower trajectory and clearly with a large volume of avoided emissions with respect to previous expectations. There is some room for optimism, however, that further increases in greenhouse gas emissions in China might be averted for several years if energy efficiency improvements continue, markets continue to open up and lead to price reforms, persistent inefficiencies in the coal industry are removed, and natural gas continues to penetrate at a rapid rate. Much will depend on the vitality of the Chinese economy in the coming years.

We note that two other important species that influence radiative forcing, black carbon (BC) and sulfate, have been affected by these same trends in China. The importance of $\mathrm{BC}$ aerosol has been stressed by Hansen et al. (16) and Jacobson (17); its contribution to positive radiative forcing (warming) in the modern era may be second only to $\mathrm{CO}_{2}$. Although we have insufficient information on changes in combustors and particulate controls to develop complete annual trends for $\mathrm{BC}$, we do have two data points for 1995 and 2000. Our estimate is that $\mathrm{BC}$ emissions declined by $32 \%$, from $1.34 \mathrm{Tg}$ in 1995 (18) to $0.91 \mathrm{Tg}$ in 2000 (19). The reduction in coal use was reinforced by a transition in urban areas from the use of raw coal to "smokeless" coal briquettes. Sulfur dioxide is converted in the atmosphere to sulfate aerosol, which has a negative radiative forcing (cooling). Emissions of $\mathrm{SO}_{2}$ declined from a peak of 26.2 $\mathrm{Tg}$ in 1996 (20) to an estimated $20.8 \mathrm{Tg}$ in 2000 (19), a reduction of $21 \%$.

A global-model calculation (17) of the effects of the 1995 to 2000 emission changes in China yields estimated changes in global mean temperatures over a 100 -year period of $+0.04 \mathrm{~K}$ for $\mathrm{SO}_{2},-0.026 \mathrm{~K}$ for $\mathrm{BC},-0.003 \mathrm{~K}$ for $\mathrm{CO}_{2}$, and $+0.001 \mathrm{~K}$ for $\mathrm{CH}_{4}$, an overall net change in global mean temperatures of $+0.012 \mathrm{~K}( \pm 0.02 \mathrm{~K})$. In sum, the changes in emissions in China from 1995 to 2000 could slightly enhance global warming over a 100 -year period, because of the dominant effect of the $\mathrm{SO}_{2}$ reductions. Whereas this calculation illustrates the need to address aerosol species in global-warming policies (16), it is not intended to detract from the importance of the reductions in the conventional greenhouse gases $\mathrm{CO}_{2}$ and $\mathrm{CH}_{4}$ that China has achieved. China's experience suggests that there are actions that can be taken today in developing countries that would reduce their contribution to global greenhouse gas emissions far below "business-as-usual" projections.

\section{References and Notes}

1. N. Nakicenovic et al., Emissions Scenarios [A Special Report of the Intergovernmental Panel on Climate Change (IPCC), Cambridge Univ. Press, Cambridge, 2000].

2. J. E. Sinton, D. G. Fridley, Energy Policy 28, 671 (2000).

3. T. G. Rawski, China Perspect. 33, 25 (2001).

4. International Energy Annual 1999 [U.S. Department of Energy Report DOE/EIA-0219(99), Department of Energy, Washington, DC, 2001].

5. It has been claimed that China achieved these reductions in energy use and greenhouse gas emissions while maintaining a high rate of economic growth Overall GDP growth of $36 \%$ since the mid-1990s has been widely cited (see, e.g., New York Times, 15 June 2001; Natural Resources Defense Council, available at www.nrdc.org/globalwarming/achinagg.asp). It is now suspected that Chinese statistics claiming 5 to 6\% annual GDP growth in the period 1997 to 1999 are exaggerated (3).

6. Revised 1996 IPCC Guidelines for National Greenhouse Gas Inventories, J. T. Houghton et al., Eds. (IPCC, Bracknell, UK, 1997).

7. China Climate Change Country Study (Tsinghua Univ. Press, Beijing, China, 1999).

8. Energy data for China are taken from (2), updated by official Chinese government data for 1999 and 2000, as affirmed in Q. Y. Wang, Nengyuan Zhengce Yanjiu [Energy Policy Res.], 1, 57 (2001) (in Chinese) and National Bureau of Statistics, Zhongguo Tongji Zhaiyao [China Statist. Abstr.] (China Statistics Press, Beijing, China, 2001) (in Chinese).

9. China Statistical Yearbook 2001 (China Statistics Press, Beijing, China, 2001) and earlier editions.

10. X.-Q. Zhang, D. Xu, "Potential carbon sequestration in forests of China" (Technical Report, Forest Ecology and Environment Institute, Chinese Academy of Forestry, Beijing, China, 2001)

11. The U.S. Energy Information Administration has reported that China's $\mathrm{CO}_{2}$ emissions from fossil fuel use declined by $17 \%$ between 1997 and 1999 (4). This estimate has been widely cited (e.g., New York Times, 15 June 2001; Natural Resources Defense Council, www.nrdc.org/globalwarming/achinagg.asp). We estimate a decline of $7 \%$ for fossil fuel use in this period. The difference is primarily due to the recent reassessment of 1999 coal use by the Chinese government (8).

12. A report from the U.S. Embassy in Beijing, The Controversy over China's Reported Falling Energy Use (August 2001), available at www.usembassy-china.org.cn/ english/sandt/energy_stats_web.htm, expressed doubt that energy use fell in China during the late 1990s, based on the unreliability of official statistics. An article based on this viewpoint was subsequently published in the Washington Post, 14 August 2001.

13. Q. Dou et al., Technology Assessment and Development Strategies of Coalbed Methane Recovery and Utilization (China Coalbed Methane Clearinghouse, Beijing, China, 2000)

14. J. G. J. Olivier et al., "Description of EDGAR Version 2.0" (Report 771060 002, National Institute of Public Health and the Environment, Bilthoven, the Netherlands, 1996).

15. J. E. Sinton, D. G. Fridley, Sinosphere 4, 3 (2001).

16. J. Hansen, M. Sato, R. Ruedy, A. Lacis, V. Oinas, Proc. Natl. Acad. Sci. U.S.A. 97, 9875 (2000).

17. M. Z. Jacobson, Nature 409, 695 (2001).

18. D. G. Streets et al., Atmos. Environ. 35, 4281 (2001).

19. Data developed for NASA's TRACE-P (Experimental and Theoretical Studies of Transport and Chemical Evolution over the Pacific) program. For information on the methodology used and the gridded emissions data, see the following Web site: www.cgrer.uiowa.edu/ people/carmichael/ACESS/Emission-data_main.html.

20. D. G. Streets, N. Y. Tsai, H. Akimoto, K. Oka, Atmos. Environ. 34, 4413 (2000)

21. This work was supported by the U.S. Department of Energy, Office of Fossil Energy, under contract W-31109-Eng-38 with Argonne National Laboratory. The opinions are those of the authors alone and not the institutions with which they are affiliated. 